\title{
Acute Myeloid Leukemia Treatment Outcomes: First Report from Single Center Retrospective Study in Kazakhstan
}

Jamilya Saparbay ( $\nabla$ dzhamilyasaparbay@gmail.com )

National Research Oncology Center

Gulnara Kulkayeva

National Research Oncology Center

Vadim Kemaykin

National Research Oncology Center

Aset Kuttymuratov

National Research Oncology Center

Zhanna Burlaka

National Research Oncology Center

Gulnur Zhakhina

National Research Oncology Center

Aisha Adusheva

National Research Oncology Center

Saltanat Dosayeva

National Research Oncology Center

\section{Research Article}

Keywords: Acute myeloid leukemia, white blood cell counts, survival analysis, cytogenetic prognosis, hematopoietic stem cell transplantation.

Posted Date: July 30th, 2021

DOl: https://doi.org/10.21203/rs.3.rs-757253/v1

License: (c) (i) This work is licensed under a Creative Commons Attribution 4.0 International License.

Read Full License 
Article type: original article

Title: Acute myeloid leukemia treatment outcomes: First report from single center retrospective study in Kazakhstan

\author{
Kulkayeva G.U. ${ }^{1}$, Kemaykin V.M. ${ }^{2}$, Kuttymuratov A.M. ${ }^{3}$, Burlaka Z.I. ${ }^{4}$, Saparbay J.Z. ${ }^{5}$, Zhakhina G.T. $^{6}$, \\ Adusheva A.A. ${ }^{7}$, Dosayeva S.D. ${ }^{8}$ \\ ${ }^{1}$ LLP «National Research Oncology Center», Kerey and Zhanibek khandar street 3, 01-0000, Nur-Sultan, Kazakhstan. \\ ORCID ID: 0000-0002-7883-211X
}

E-mail: gulnara1412@mail.ru

${ }^{2}$ Department of oncohematology and stem cell transplantation, LLP «National Research Oncology Center», Kerey and Zhanibek khandar street 3, 01-0000, Nur-Sultan, Kazakhstan. ORCID ID: 0000-0001-8470-4344

E-mail: kemaykin90@mail.ru

${ }^{3}$ Department of oncohematology and stem cell transplantation, LLP «National Research Oncology Center», Kerey and

Zhanibek khandar street 3, 01-0000, Nur-Sultan, Kazakhstan. ORCID ID: 0000-0002-5270-2149

E-mail: aset91-91@ mail.ru

${ }^{4}$ Department of oncohematology and stem cell transplantation, LLP «National Research Oncology Center», Kerey and

Zhanibek khandar street 3, 01-0000, Nur-Sultan, Kazakhstan. ORCID ID: 0000-0002-0202-137X

21 E-mail: burlakazhanna@gmail.com

${ }^{5}$ Department of hepatology, gastroenterology and organ transplantation, LLP «National Research Oncology Center»,

Kerey and Zhanibek khandar street 3, 01-0000, Nur- Sultan, Kazakhstan. ORCID ID: 0000-0002-8478-5452

E-mail: dzhamilyasaparbay@gmail.com

${ }^{6}$ Department of science, LLP «National Research Oncology Center», Kerey and Zhanibek khandar street 3, 01-0000, Nur-Sultan, Kazakhstan. ORCID ID: 0000-0002-1001-1374

27 E-mail: gulnur.zhakhina@alumni.nu.edu.kz

${ }^{7}$ Department of oncohematology and stem cell transplantation, LLP «National Research Oncology Center», Kerey and

Zhanibek khandar street 3, 01-0000, Nur-Sultan, Kazakhstan. ORCID ID: 0000-0003-0049-4437

E-mail: aishaalbert34@gmail.com

${ }^{8}$ Department of oncohematology and stem cell transplantation, LLP «National Research Oncology Center», Kerey and Zhanibek khandar street 3, 01-0000, Nur-Sultan, Kazakhstan. ORCID ID: 0000-0001-7845-6241

E-mail: saltanat-dosaeva@mail.ru

*Correspondence to dzhamilyasaparbay@ gmail.com 


\section{Abstract}

2 Acute myeloid leukemia (AML) is the most common hematological malignancy in adults. In the last decade,

3 internationally approved AML treatment guidelines, including hematopoietic stem cell transplantation are widely used in

4 Kazakhstan. The categorization of acute myeloid leukemia was done according to the French-American British

5 classification. The prognosis of patients at the time of diagnosis was determined by cytogenetic tests following the

6 guidelines of the European LeukemiaNet. The overall survival and event-free survival were analyzed using the Kaplan-

7 Meier method, and hazard ratios were defined with Cox regression.

8 Totally 398 patients with AML were treated in the National Research Oncology Center between 2010 and 2020. The

9 mean age was 38.3 years. We have found the correlation between ethnicity, cytogenetic group, white blood cell count, and 10 treatment approaches with overall and event-free survival. There was a significantly longer OS in a cytogenetic group 11 with a good prognosis compared with intermediate and poor prognosis. The median survival time in the group with a good 12 prognosis was 43 months, 23 months in the intermediate group ( $\mathrm{p}=0.7)$, and 12 months in the poor prognosis group 13 ( $\mathrm{p}=0.016)$. There was a significantly longer OS for the group of patients who received hematopoietic stem cell 14 transplantation (HSCT), 52 months versus 10 months in the group who received chemotherapy only, p-value $<0.0001$. 15 Prognostic factors, such as cytogenetic group, initial WBC count, and treatment approaches are significantly associated 16 with patient survival. Our study data were consistent with previous reports.

\section{Keywords:}

19 Acute myeloid leukemia; white blood cell counts; survival analysis; cytogenetic prognosis; hematopoietic stem cell 20 transplantation.

\section{Abbreviations}

23 AML - acute myeloid leukemia

24 DNR - daunorubicin

25 Doxo - doxorubicin

26 EFS - event-free survival

27 FAB - French-American British classification

28 HSCT - hematopoietic stem cell transplantation

29 IDA - idarubicin

30 OS - overall survival

31 WBC - white blood cell 
According to the Kazakhstan National Cancer Institute, hematological malignancies represent $4.7 \%$ of all cancers, $5^{\text {th }}$ place among both sexes in Kazakhstan. Morbidity due to hematological cancer is in $4^{\text {th }}$ place among all cancer-related deaths in Kazakhstan [1]. Based on to Globocan data, 759 new cases of leukemia were registered in Kazakhstan in 2020, which corresponds to the $14^{\text {th }}$ place among all cancers, the growth rate comprised $2 \%$ compared with 2019 [2]. Acute myeloid leukemia (AML) is the most common acute leukemia in adults [3]. There are no data regarding the estimated number of death due to AML in Kazakhstan. AML is a group of blood cell cancers originating from hematopoietic precursors in the bone marrow and resulting in a conglomeration of poorly differentiated myeloid cells infiltrating bone marrow, peripheral blood, and other organs [4]. Blood disorder develops due to the acquisition of chromosomal translocations and multiple genetic mutations by leukemic stem cells [5-7]. Genetic events are usually associated with environmental influence, other blood disorders, tobacco use, and previous chemotherapy [8-9]. It is well known that AML incidence increases with age. The median age of people being diagnosed is 65 years [10]. Various factors were proved to influence the AML incidence and clinical outcome. The incidence increases with age with approximately 2 and 20 cases per 100,000 population for those under and over 65 years, respectively [11]. The male/female ratio is approximately 5:3 [12]. There are little data regarding AML epidemiology, treatment approaches, and clinical outcomes in Kazakhstan. Here we present a single-center experience of AML treatment outcome.

\section{Methods}

18 The data were retrospectively analyzed, and all ethical principles of the Helsinki Declaration have been followed. The Ethical Committee of the National Research Oncology Center (permit number №11) approved the study.

Acute myeloid leukemia classification

21 The further division of AML into its subtypes was done according to the French-American British (FAB) classification. 22 It sorts AML from M0 to M7, depending on the type of cell where leukemia developed and the maturity of these cells 23 [13]. Moreover, this categorization takes into account the symptoms that show the whole picture of the patient's condition. Molecular genetic stratification of patients by risk groups ELN 2017

Depending on disease pathogenesis, European LeukemiaNet defined three genetic groups for the classification of AML: poor cytogenetic prognosis, intermediate prognosis, and favorable prognosis [14]. The categorization was based on genetic

27 abnormalities correlated with clinical characteristics. The poor prognosis included translocations $\mathrm{t}(6 ; 9), \mathrm{t}(9 ; 22)$, inversions

28 inv(3), deletions, mutations of RUNX1, ASXL1, and TP53. As intermediate ones were categorized $t(9 ; 11)$, mutations of 29 NPM1 and FLT3-ITDhight, and anomalies not classified within poor or favorable prognosis. Translocations $\mathrm{t}(8 ; 21)$, $\mathrm{t}(16 ; 16)$, inversion of chromosome 16, RUNX1-RUNX1T1, and some mutations of NPM1 were categorized as favorable prognosis.

Induction therapy

33 Chemotherapy is the main treatment of AML to reach remission and complete response. The induction therapy was chosen 34 according to the clinical protocol of diagnostics and treatment of AML approved by the Ministry of Health of the Republic 35 of Kazakhstan [15]. Common procedures include cytarabine for 7 days, which is followed by 3 days of anti-tumor 
antibiotics. Mostly used anti-tumor antibiotics were daunorubicin (DNR), idarubicin (IDA), and doxorubicin (Doxo).

2 There were other antibiotics used in the frame of chemotherapy, and they were united in one category 'others'.

3 There were different complications after chemotherapy: multiple organ failure syndrome, disseminated intravascular

4 coagulation, anal fissures, sepsis, paraproctitis, pneumonia, Hand-Foot Syndrome, candidiasis, polysinusitis, and others.

5 Most common were febrile neutropenia, sepsis, and aspergillosis.

$6 \quad$ Statistical analysis

7 All data were analyzed with statistical software STATA 14.0. For bivariate analysis, the outcome was taken as the 8 dependent variable, and association with predictors was checked with t-tests and chi-square tests. Kaplan-Meier curves 9 were used to show the overall survival (OS) and event-free survival (EFS) of patients. A Long-rank test was used to access 10 the equality of survival functions, and Cox regression was applied to define the Hazard Ratios. The significance level was 11 set at 0.05 .

\section{Results}

13 Totally 398 patients with AML were treated in the National Research Oncology Center between 2010 and 2020. The final 14 study included 371 patients, 27 patients were excluded from the study, patients were excluded if they were lost from 15 follow-up or a history of prior treatment. Patients were predominantly younger than 60 years old (95.1\%). The mean age 16 of the study group was $38.3( \pm 13)$ years old. There was no significant difference in the gender of the patients. Clinical17 demographical characteristics are shown in Table 1. There was a statistically significant difference in overall survival (OS) 18 and event-free survival (EFS) related to the patient's age. Median OS (Figure 1a) of the 17 months for patients younger 19 than 60 years old versus 4 months for the group of patients older than 60 years (p-value 0.0001; HR=2.6). The median 20 EFS (Figure 1b) was 14 months for the younger group versus 7 months for the group older than 60 years (p-value 0.0010; 21 HR- 2.24). Kazakhstan is a multinational country, in our cohort study we also compared OS and EFS related to race 22 (Figure 2). Our data showed that there was a significant difference in OS between the Asian and Caucasians group of 23 patients, 19 and 10 months respectively $(\mathrm{p}=0.0001)$. The event-free survival was significantly related to gender, although 24 not the overall survival (Figure 3). The median EFS in females was 18 months and 14 months in males. There was a 25 significantly longer OS in a cytogenetic group with a good prognosis compared with intermediate and poor prognosis 26 (Figure 4). The median survival time in the group with a good prognosis was 43 months, 23 months in the intermediate 27 group ( $\mathrm{p}=0.7$ ), and 12 months in the poor prognosis group ( $\mathrm{p}=0.016)$. A similar significance was observed for EFS (Figure 28 5), median survival in the favorable prognosis group was 24 months versus 11 months in the poor prognosis group 29 ( $\mathrm{p}=0.036)$. There was a significantly longer OS for the group of patients who received hematopoietic stem cell 30 transplantation (HSCT), 52 months versus 10 months in the group who received chemotherapy only, p-value $<0.0001$ 31 (Figure 6). Our analysis showed that OS and EFS in a group of patients with white blood cell (WBC) lower than $30 \times 10^{9} / \mathrm{L}$ 32 was significantly higher compared with the group with a WBC count of more than $30 \times 10^{9} / \mathrm{L}$ at the time of diagnosis, 20 33 months vs 13 months and 17 months vs 10 months respectively (Figure 7). The median survival time for those, who 34 underwent allogeneic stem cell transplantation was 43 months, while for haploidentical stem cell transplantation patients 35 it was 39 months, and the difference was not statistically significant, $\mathrm{p}=0.28$ (Figure 8). 
1 We found that the development of febrile neutropenia after chemotherapy was significantly associated with a negative

2 outcome. In this study, $63.9 \%$ of patients died; $67 \%$ died due to the disease progression, the second most common cause

3 of death was an infection.

\section{Discussion}

5 The current study reports a 10-year single-center experience of AML treatment in Kazakhstan. The National Research

6 Oncology Center is one of the largest centers in Central Asia. In our study, we analyzed the incidence, death, and other

7 epidemiological data of AML, based on the medical record database of our center during the past 10 years. There is scarce 8 epidemiological data on AML in Kazakhstan.

9 Although population data says that acute myeloid leukemia occurs mostly in adults [16], the mean age of our patients was

1038 years. It can be explained by the fact that initially there was a selection bias to perform hematopoietic stem cell 11 transplantation. AML can be cured at younger ages more successfully than for those older than 60 years [17]. There is no 12 clear cut-off point in literature for age to predict prognosis; however, the separation as younger than 60 and older showed 13 significant results in both overall survival and event-free survival. Older individuals had for $160 \%$ more risk of death due 14 to disease (Figure 1a), and this result is consistent with other research outcomes [18].

15 The data showed significantly better event-free survival for females $(\mathrm{HR}=1.38)$. The trend of higher survival rates among 16 women diagnosed with AML also was previously reported [19]. However, the cause of this phenomenon is still to be 17 discovered. Moreover, ethnicity was also significantly associated with outcome, where Asians showed approximately two 18 times longer median overall survival time compared to Caucasians. The impact of ethnicity on survival matches with the 19 results of other countries, and such tendency could be explained with different genetic alterations among races [20].

20 Similar to the literature, cytogenetic prognosis and white blood cell count was significantly related to the outcome. Both 21 of these factors are key points in the diagnosis and treatment of AML. Consistent with the literature, the data of the present 22 study shows that poor cytogenetic prognosis according to ELN classification at the time of diagnosis leads to higher 23 mortality rates compared to intermediate and favorable ones [21]. For WBC count, a level at 30x10 $/ \mathrm{L}$ was taken as a cut24 off point and showed a significant association between high white blood cell count at the diagnosis time and lower overall 25 and event-free survival of patients. It is consistent with the results of other researchers [22-23]. The possible explanation 26 is that a high WBC count is associates with the possible progression of leukocytosis, which affects the prognosis of patients 27 [24].

28 The primary induction therapy with IDA showed a significant association with a favorable outcome compared to 29 daunorubicin (DNR) and doxorubicin (Doxo), 52\% vs 37\% and 31\% respectively. Hanyu Wang and colleagues performed 30 a meta-analysis comparing the effect of different therapies on AML patient survival, and our results agree with the findings

31 [25]. This could be a turning point to change the Kazakhstani protocol of AML treatment, where DNR and IDA are equally 32 suggested for induction therapy.

33 Although the survival depending on the type of stem cell transplantation did not give statistical significance, it has medical 34 importance for doctors and patients. The lack of donors for haploidentical stem cell transplantation is a big issue in 35 Kazakhstan. Moreover, it should be noticed that the HSCT was initiated in our country only in 2010. This study gives an 36 overview of the first 10-year experience's results, implementation of acute myeloid leukemia treatment guidelines in 37 Kazakhstan. The main limitation is a bias by age: the data is scarce of adults older than 60 years. It can be improved in 38 further research, which can include all ages and be a prospective study. 
1

\section{$7 \quad$ Funding}

8 The authors receive no funding for this study.

\section{Conflict of Interest}

10 No potential conflict of interest relevant to this article was reported.

\section{Availability of data and material}

12 The data that support the findings of this study are available from the corresponding author upon reasonable request.

\section{Authors' contribution}

14 GK: research design; data analysis and writing the paper; JS: research design; data analysis and writing the paper. VK:

15 research design, writing the paper. AK research design; data collection writing the paper. GZ: data analysis, writing the 16 paper; ZB: data collection. AA: data collection; SD: data collection.

\section{Acknowledgments}

18 We would like to thank the transplant team of the National Research Oncology Center for their great work throughout 10 19 years.

\section{Ethical approval}

21 The Ethical Committee of the National Research Oncology Center (permit number №11) approved the study. 
Table legends

2

3 Table 1. Demographic and medical characteristic of patients $(\mathrm{N}=371)$

4

5

$6 \quad$ Figure legends

7

8 Figure 1. Age-related survival. (A) Overall survival and (B) event-free survival.

9 Figure 2. Race-related survival. (A) Overall survival and (B) event-free survival.

10 Figure 3. Gender-related survival. (A) Overall survival and (B) event-free survival.

11 Figure 4. Overall survival in respect to cytogenetic prognosis.

12 Figure 5. Event-free survival in respect to cytogenetic prognosis.

13 Figure 6. Survival in respect to hematopoietic stem cell transplantation.

14

Figure 7. Survival in respect to white blood cell count. (A) Overall survival and (B) event-free survival.

15

Figure 8. Overall survival in respect to type of stem cell transplantation: allogeneic vs haploidentical.

16

17

18

19

20

21

22

23

24

25

26

27

28 
1. Kazakh Research Institute of Oncology and Radiology (2020) Pokazateli oncologicheskoi sluzhby-RespublikiKazakhstan-za-2019-g; oktyabr 2020-g

2. Kazakhstan- Globocan Observatory; http://gco.iarc.fr > data > 398-kazakhstan-fact-sheets

3. Yamamoto JF, Goodman MT (2008) Patterns of leukemia incidence in the United States by subtype and demographic characteristics, 1997-2002. Cancer Causes Control 19: 379-390.

4. Grove C., Vassiliou G. (2014) Acute myeloid leukaemia: a paradigm for the clonal evolution of cancer? Disease Models \&Mechanisms 7(8):941-951.

5. Gilliland DG. (1998) Molecular genetics of human leukemia. Leukemia 12(Suppl 1):S7-12

6. Dash A, Gilliland DG.(2001) Molecular genetics of acute myeloid leukaemia. Best Pract Res Clin Haematol 14(1):49-64

7. Gilliland DG, Tallman MS. (2002) Focus on acute leukemias. Cancer Cell 1(5): 417-20

8. Patel JP, Gonen M, Figueroa ME, Fernandez H, Sun Z, Racevskis J et al. (2012) Prognostic relevance of integrated genetic profiling in acute myeloid leukemia. N Engl J Med 366: 1079-1089.

9. Cancer Genome Atlas Research Network, Ley TJ, Miller C. et al (2013) Genomic and epigenomic landscapes of adult de novo acute myeloid leukemia. N Engl J Med 2013; 368: 2059-2074.

10. Appelbaum FR, Gundacker H., Head DR., Slovak ML., Willman CL et al. (2006) Age and acute myeloid leukemia. Blood 107(9): 3481-3485

11. Forman D, Stockton D, Moller H, et al. (2003) Cancer prevalence in the UK: results from the EUROPREVAL study. Ann Oncol. 14: 648- 654.

12. Parkin DM WS, Ferlay J, Raymond L, Young J, editors. (1997) Cancer Incidence in Five Continents. Volume VII. IARC Scientific Pub. No. 143. Lyon, France: IARC Scientific Publications

13. Neame, P. B., Soamboonsrup, P., Browman, G. P., Meyer, R. M., Benger, A., Wilson, W. E., ... \& McBride, J. A. (1986) Classifying acute leukemia by immunophenotyping: a combined FAB-immunologic classification of AML.

14. Döhner, H., Estey, E., Grimwade, D., Amadori, S., Appelbaum, F. R., Büchner, T., ... \& Bloomfield, C. D. (2017) Diagnosis and management of AML in adults: 2017 ELN recommendations from an international expert panel. Blood, 129(4), 424-447.

15. Rakhimbekova G.A. and Pivovarova I.A. (2019) Clinical protocol for diagnosis and treatment of acute myeloblastic leukemia in adults. Republican Center for Health Development of the Ministry of Health and Social Development of the Republic of Kazakhstan, Protocol \#51 from January 11, 2019

16. De Kouchkovsky I. \& Abdul-Hay,M. (2016) Acute myeloid leukemia: a comprehensive review and 2016 update. Blood cancer journal, 6(7), e441-e441.

17. Saultz, J. N., \& Garzon, R. (2016) Acute myeloid leukemia: a concise review. Journal of clinical medicine, 5(3), 33.

18. Appelbaum, F. R., Gundacker, H., Head, D. R., Slovak, M. L., Willman, C. L., Godwin, J. E., Petersdorf, S. H. (2006) Age and acute myeloid leukemia. Blood, 107(9), 3481-3485

19. Acharya UH, Hslpern $\mathrm{AB}, \mathrm{Wu} \mathrm{QV}$ et al. (2018) Impact of region of diagnosis, ethnicity, age, and gender on survival in acute myeloid leukemia (AML). Journal of drug assessment, 7(1), 51-53.

20. Wei H., Wang, Y., Zhou, C., Lin, D., Liu, B., Liu, K., . . Zhang, G. (2018) Distinct genetic alteration profiles of acute myeloid leukemia between Caucasian and Eastern Asian population. Journal of hematology \& oncology, 11(1), 1-4.

21. Mrózek, K., Marcucci, G., Nicolet, D., Maharry, K. S., Becker, H., Whitman, S. P., . . Kohlschmidt, J. (2012) Prognostic significance of the European LeukemiaNet standardized system for reporting cytogenetic and molecular alterations in adults with acute myeloid leukemia. Journal of clinical oncology, 30(36), 4515

22. Nguyen, S., Leblanc, T., Fenaux, P., Witz, F., Blaise, D., Pigneux, A., . . A Auvrignon, A. (2002) A white blood cell index as the main prognostic factor in $\mathrm{t}(8 ; 21)$ acute myeloid leukemia (AML): a survey of 161 cases from the French AML Intergroup. Blood, The Journal of the American Society of Hematology, 99(10), 3517-3523. 
23. Padilha, S. L., Souza, E. J. d. S., Matos, M. C. C., \& Domino, N. R. (2015) Acute myeloid leukemia: survival analysisof patients at a university hospital of Paraná. Revista brasileira de hematologia e hemoterapia, 37, 2127.

24. Abramson, N., \& Melton, B. (2000) Leukocytosis: basics of clinical assessment. American family physician, 62(9), 2053-2060.

25. Wang, H., Xiao, X., Xiao, Q., Lu, Y., \& Wu, Y. (2020) The efficacy and safety of daunorubicin versus idarubicin combined with cytarabine for induction therapy in acute myeloid leukemia: A meta-analysis of randomized clinical trials. Medicine, 99(24). 
Figures

(A)

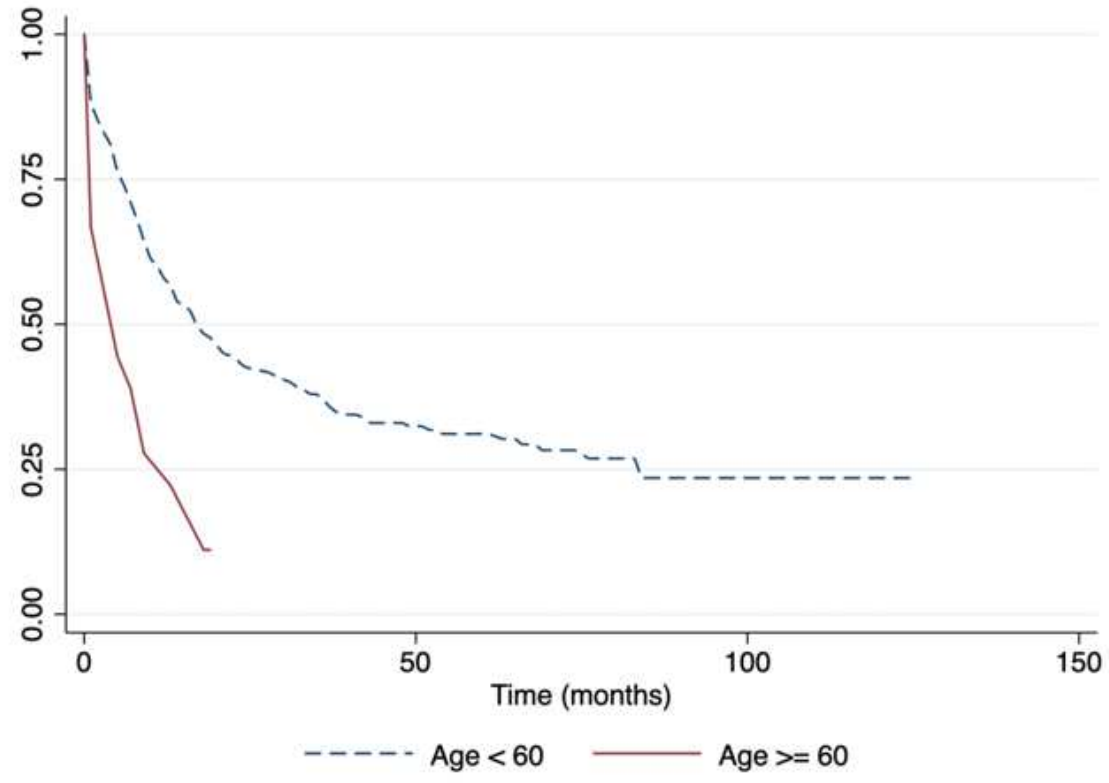

(B)

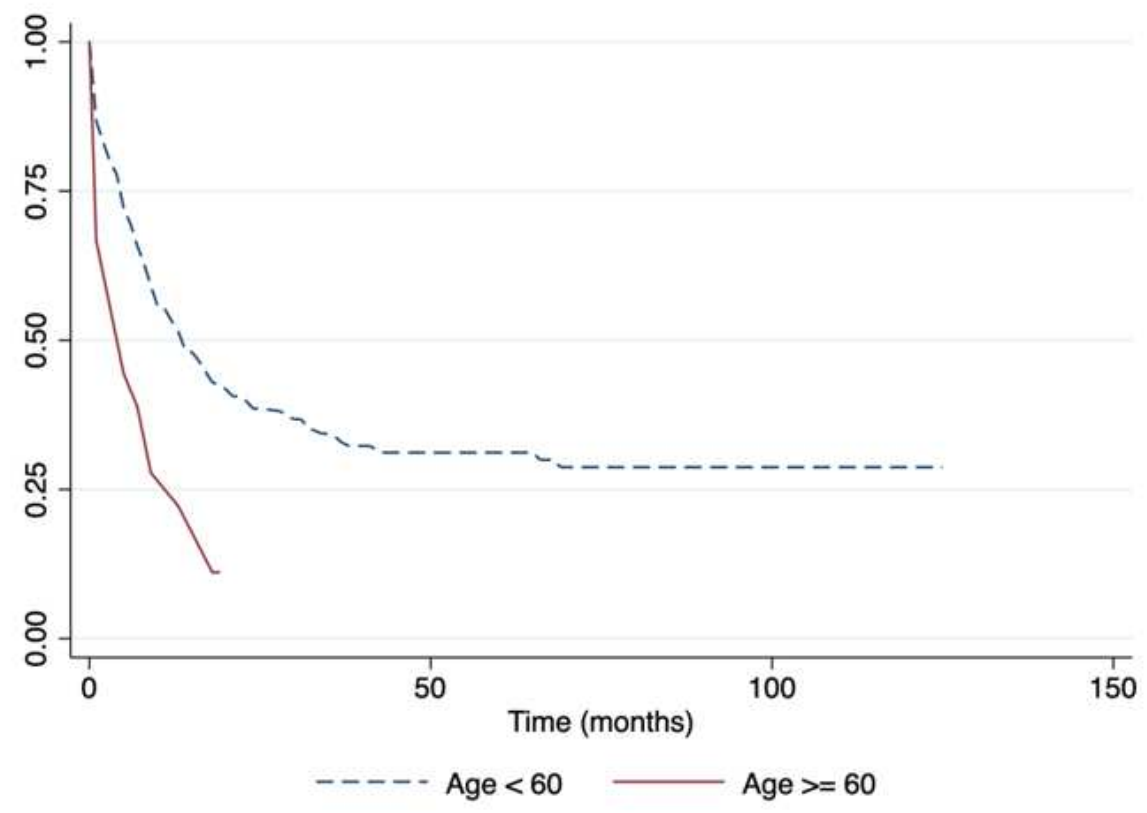

\section{Figure 1}

Age-related survival. (A) Overall survival and (B) event-free survival. 
(A)

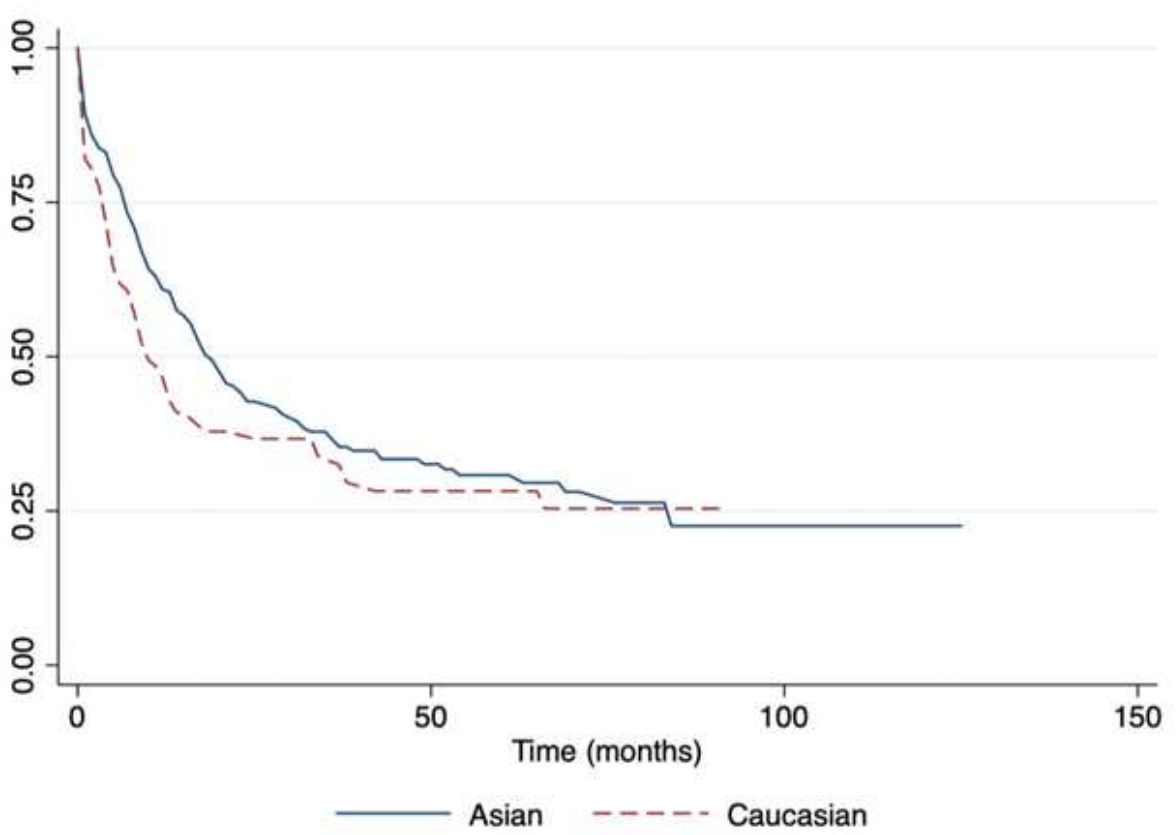

(B)

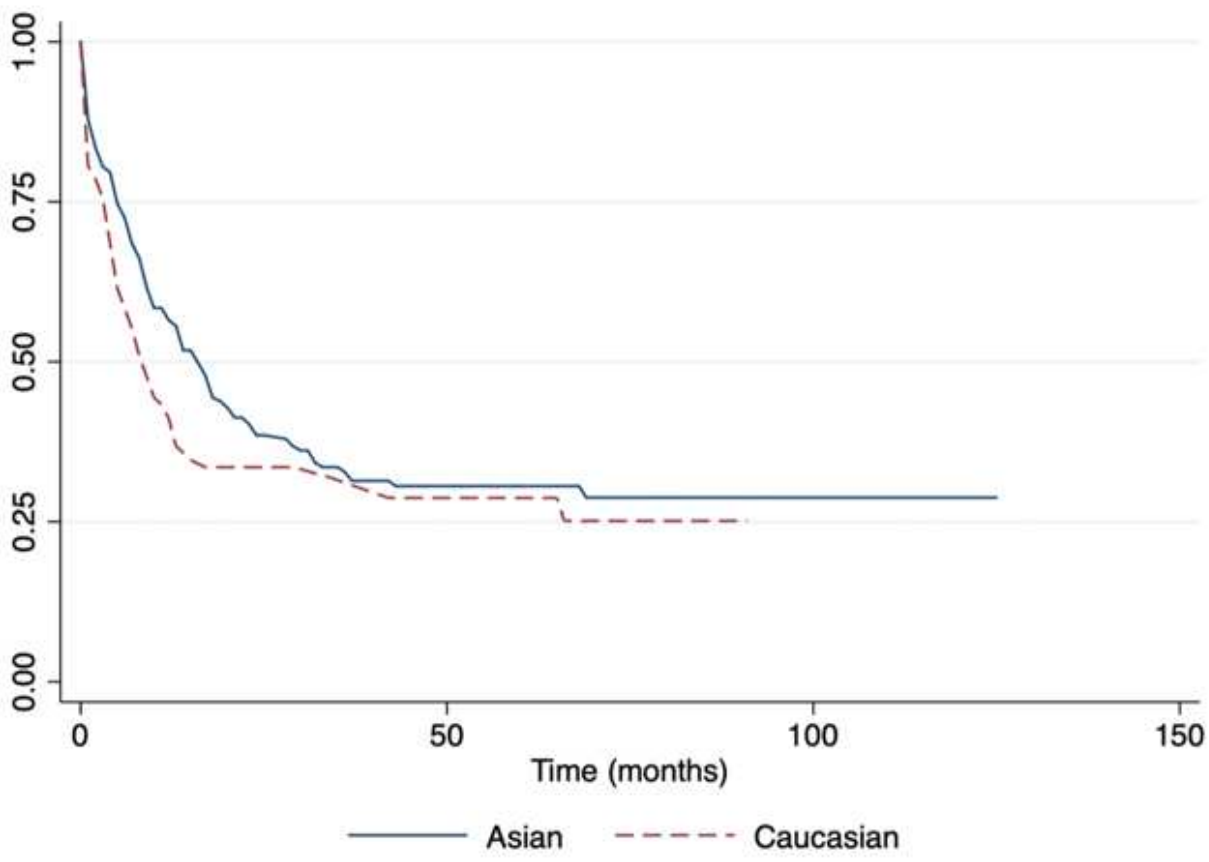

Figure 2

Race-related survival. (A) Overall survival and (B) event-free survival. 
(A)

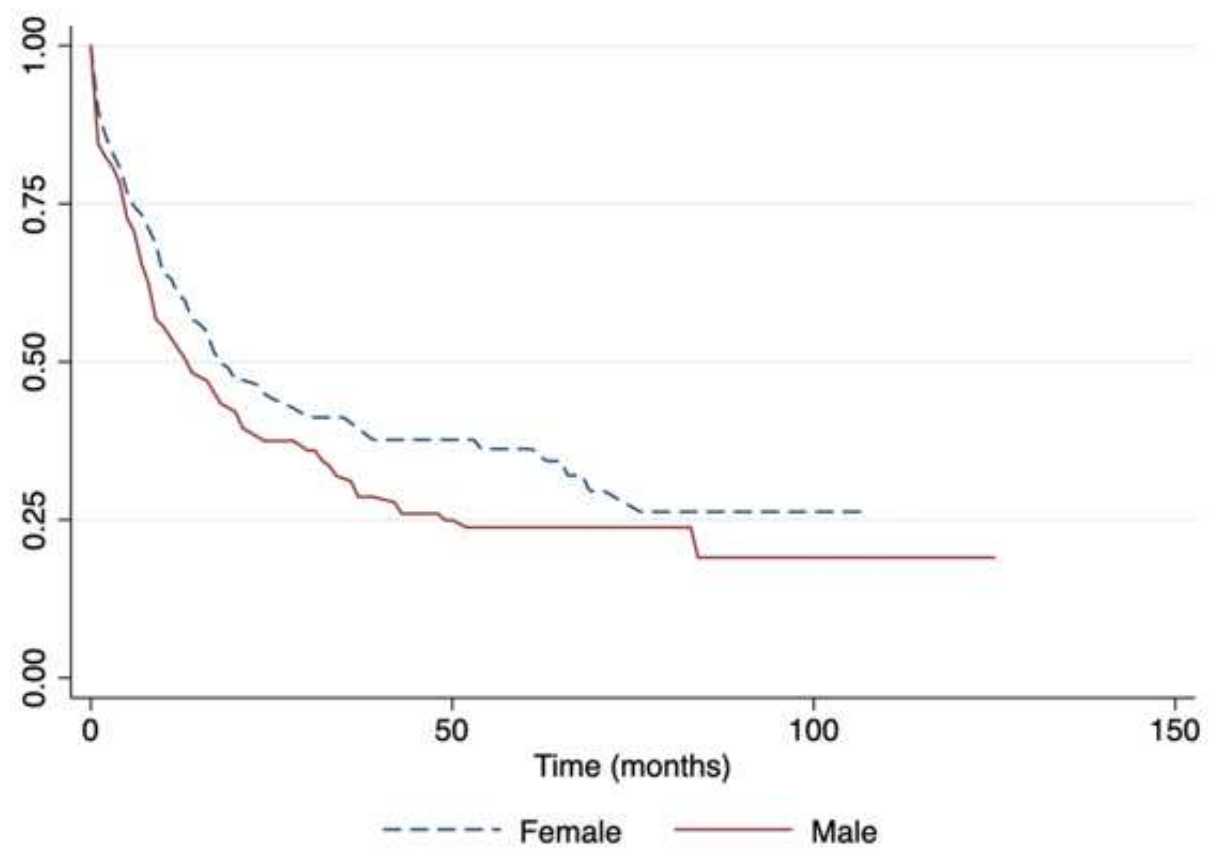

(B)

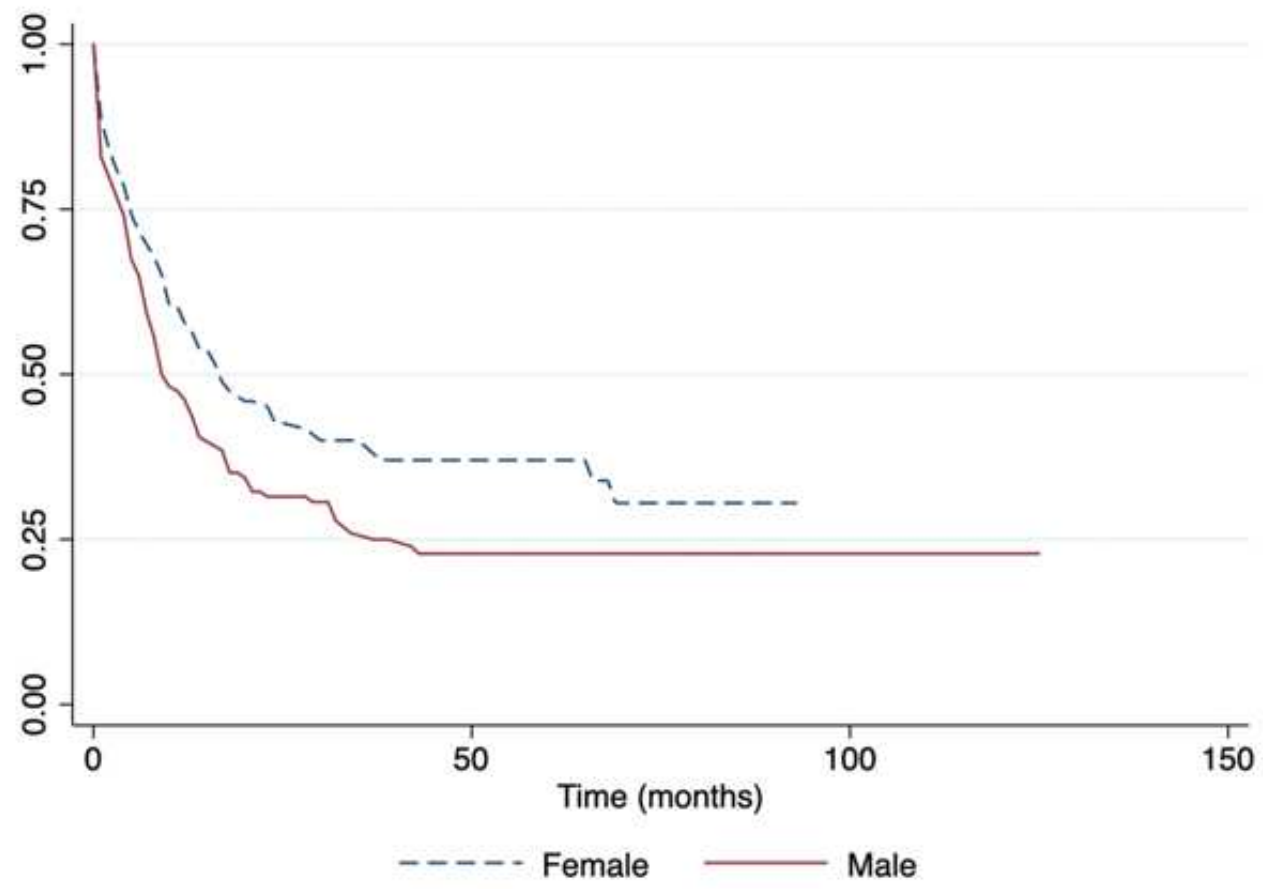

Figure 3

Gender-related survival. (A) Overall survival and (B) event-free survival. 


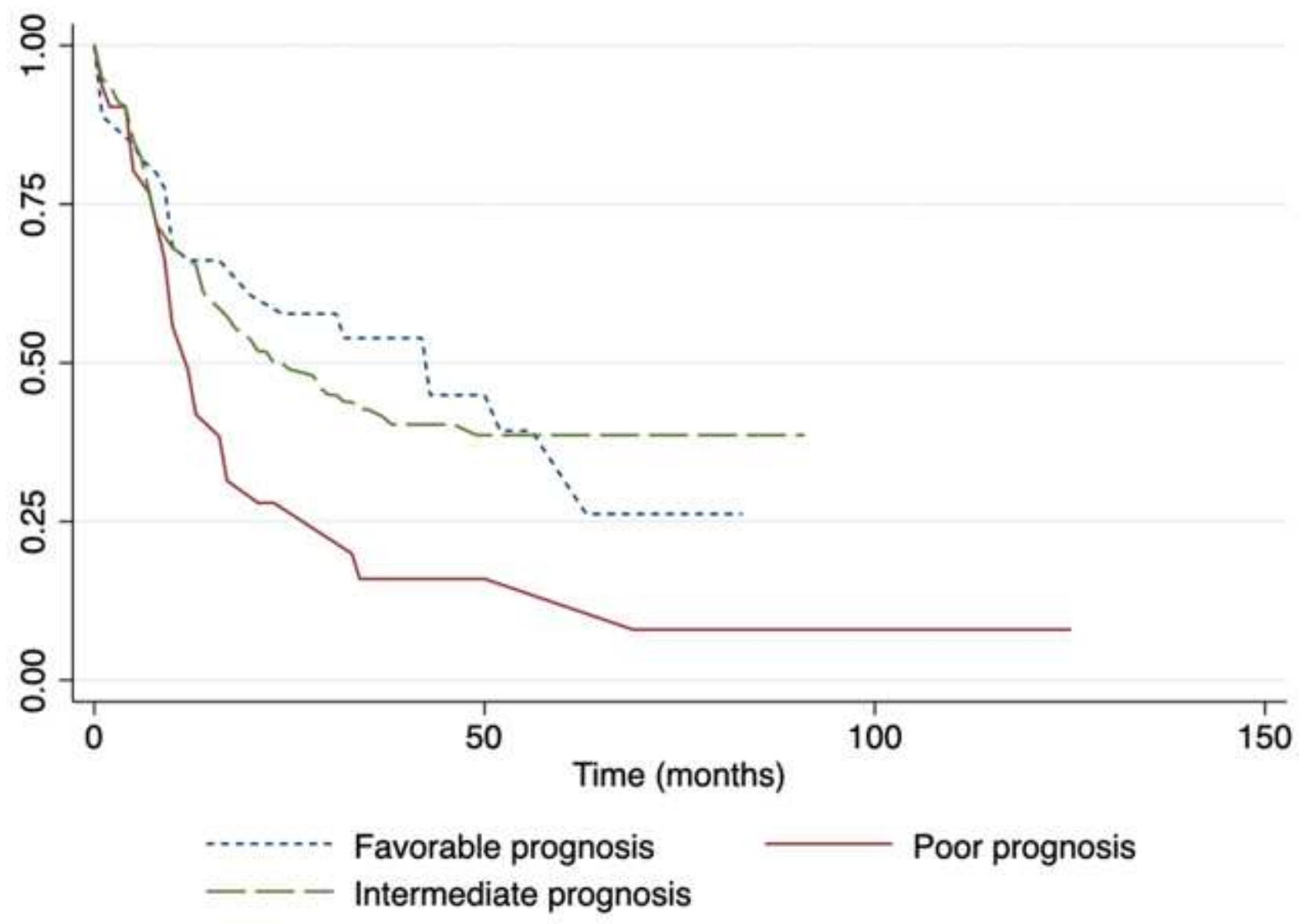

Figure 4

Overall survival in respect to cytogenetic prognosis. 


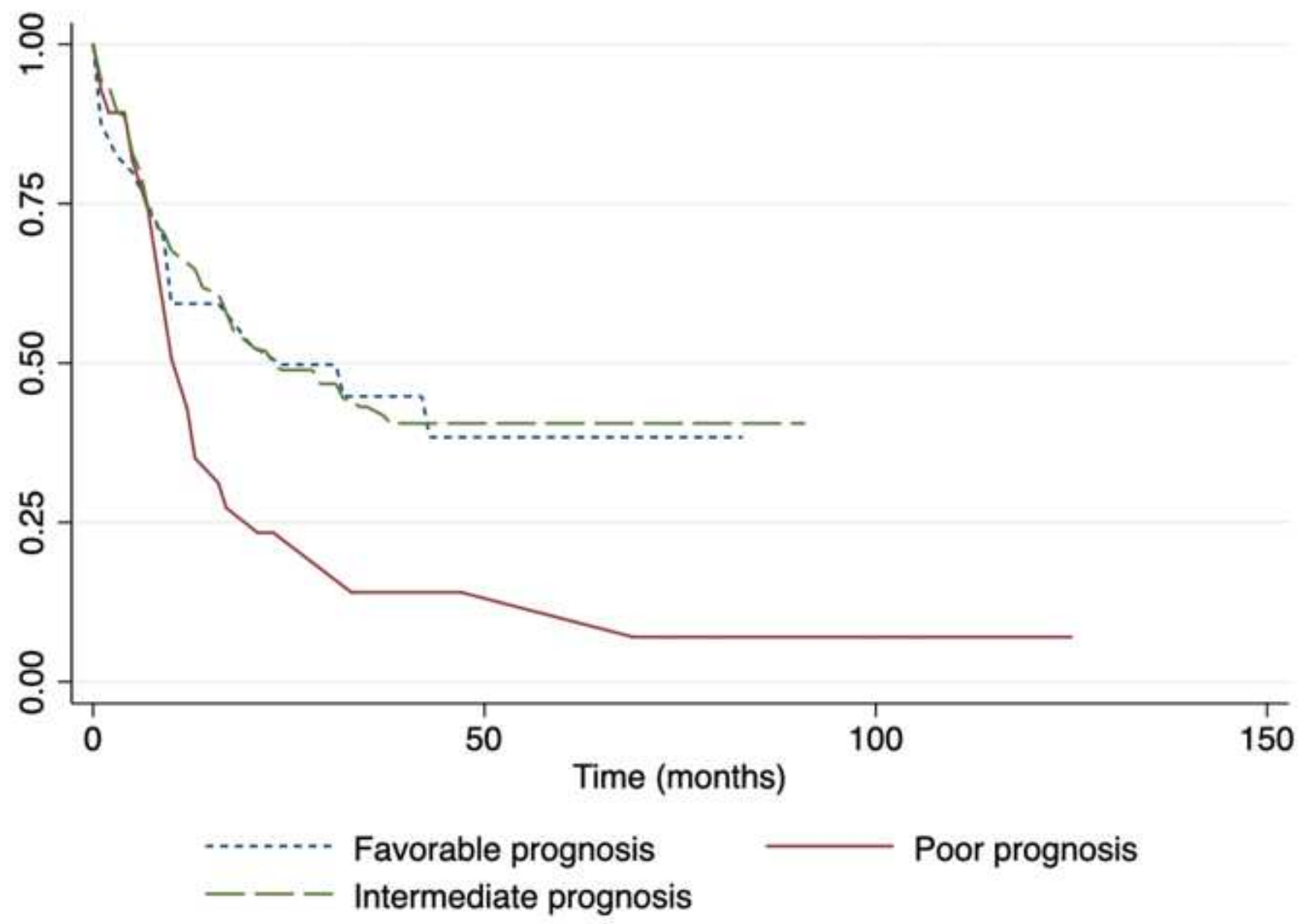

Figure 5

Event-free survival in respect to cytogenetic prognosis. 


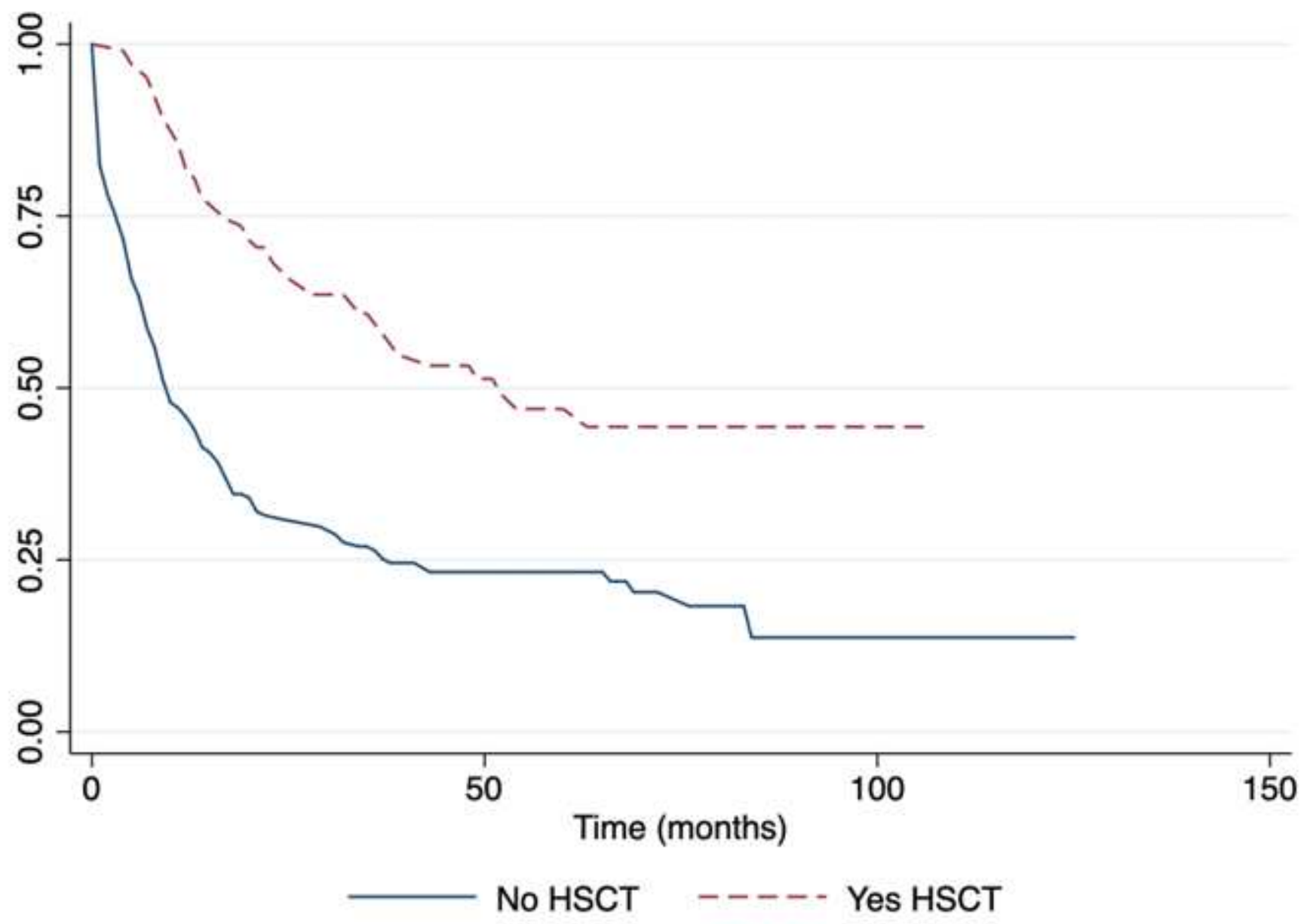

Figure 6

Survival in respect to hematopoietic stem cell transplantation. 
(A)

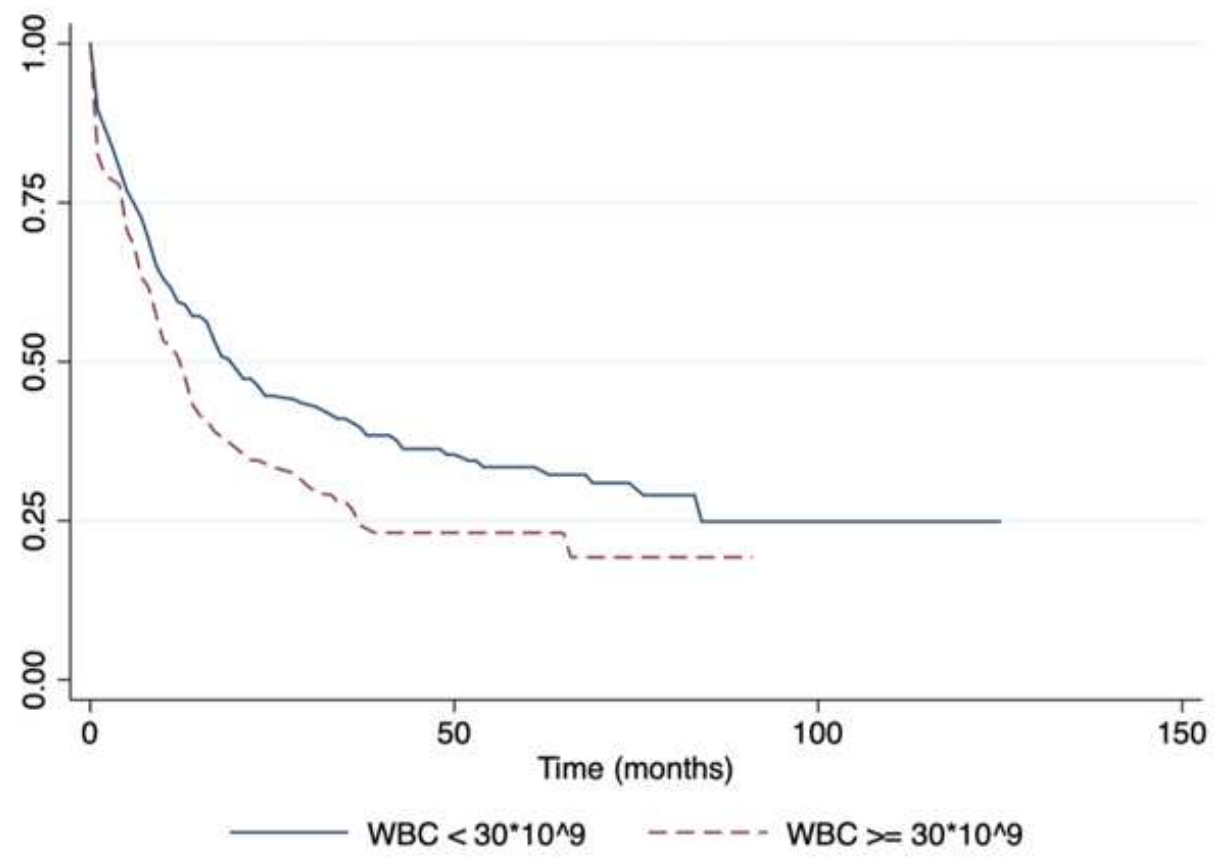

(B)

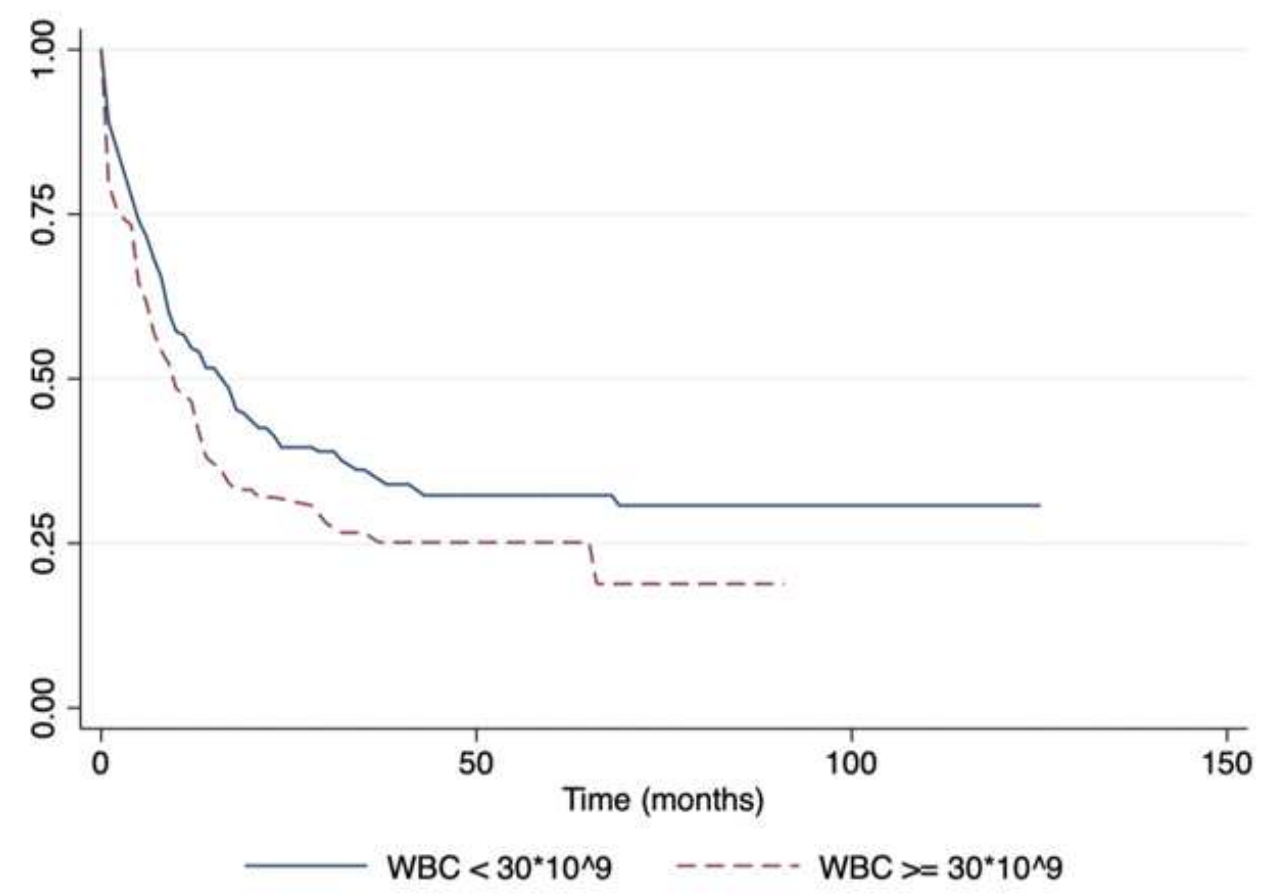

Figure 7

Survival in respect to white blood cell count. (A) Overall survival and (B) event-free survival. 


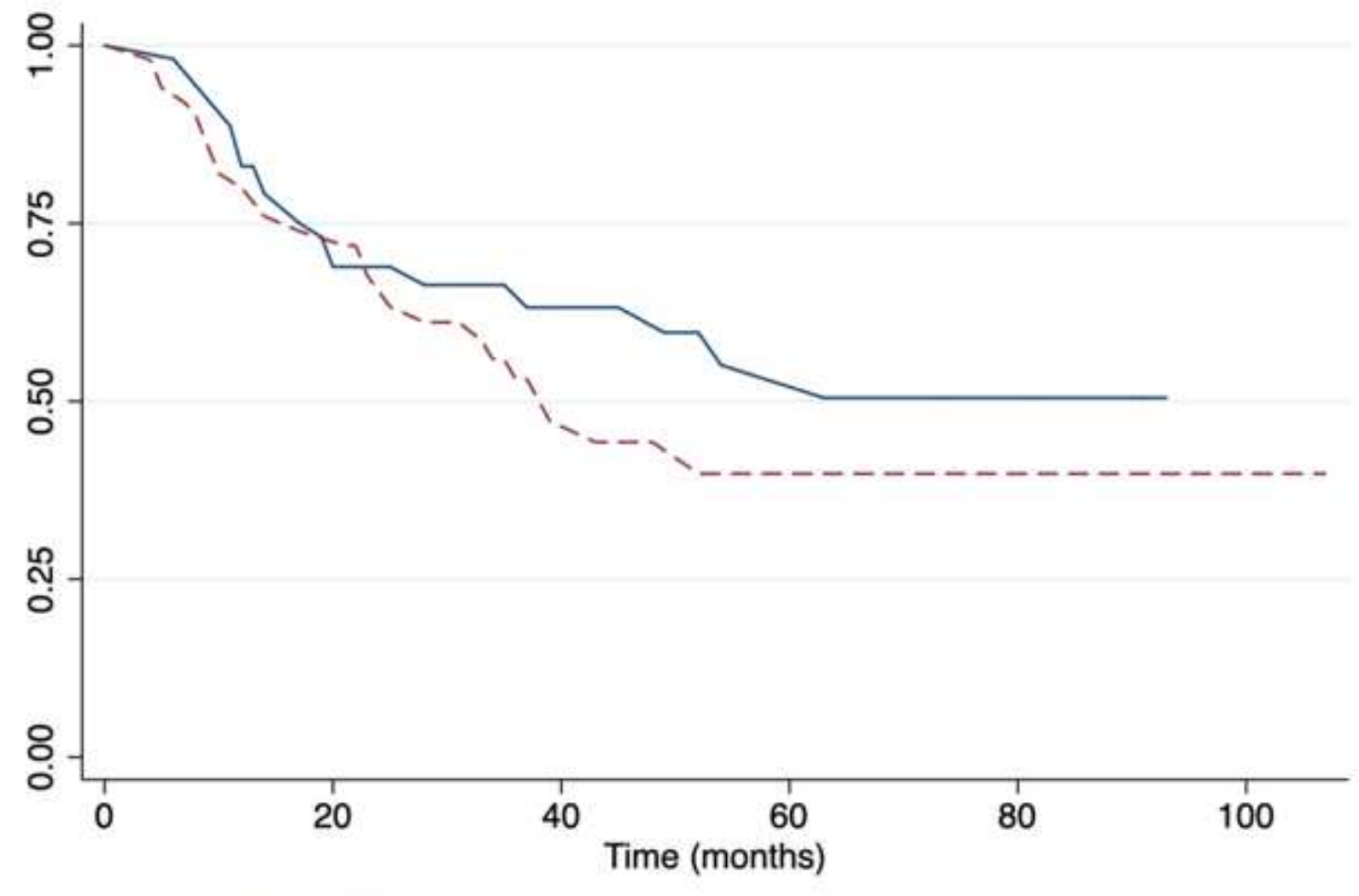

Allogeneic SCT - - - Haploidentical SCT

Figure 8

Overall survival in respect to type of stem cell transplantation: allogeneic vs haploidentical. 